Editorial

\title{
Researching Homelessness: Challenging Exclusion?
}

\author{
Isobel Anderson ${ }^{1, *}$, Maša Filipovič Hrast $^{2}$ and Joe Finnerty ${ }^{3}$ \\ ${ }^{1}$ School of Applied Social Sciences, University of Stirling, Stirling, FK9 4LA, UK; E-Mail: isobel.anderson@stir.ac.uk \\ 2 Faculty of Social Sciences, University of Ljubljana, 1000 Ljubljana, Slovenia; E-Mail: masa.filipovic@fdv.uni-lj.si \\ ${ }^{3}$ School of Applied Social Studies, University College Cork, Cork, T12 YN60, Ireland; E-Mail: j.finnerty@ucc.ie \\ * Corresponding author
}

Submitted: 20 September 2016 | Published: 20 October 2016

\begin{abstract}
This themed issue of Social Inclusion provides a timely opportunity to reflect on how contemporary research is addressing the multi-dimensional issue of homelessness around the world. The papers presented here provide a wide range of new evidence on homelessness including theoretical, methodological and empirical contributions. They draw on a range of national experiences in Europe and beyond, and addressing the issue of social inclusion and social exclusion of homeless or previously homeless people from a range of perspectives and approaches. It is hoped that the contributions to this themed issue will prove influential in terms of both scholarship and potential to enhance policy making and service delivery to some of our most excluded citizens.
\end{abstract}

\section{Keywords}

hidden homelessness; homelessness policy-making; homelessness research; policy evaluation; research networks; service user participation; social inclusion

\section{Issue}

This editorial is part of the issue "Homelessness and Social Inclusion", edited by Isobel Anderson (University of Stirling, UK), Maša Filipovič Hrast (University of Ljubljana, Slovenia) and Joe Finnerty (University College Cork, Ireland).

(C) 2016 by the authors; licensee Cogitatio (Lisbon, Portugal). This article is licensed under a Creative Commons Attribution 4.0 International License (CC BY).

As colleagues who are all active in the European Network for Housing Research group on 'Welfare Policy, Homelessness and Social Exclusion' (WELPHASE, n.d.) the invitation to edit a themed issue of Social Inclusion on our core research topic has provided a timely opportunity to reflect on how contemporary research is addressing the multi-dimensional issue of homelessness around the world. Editing this themed issue has allowed us to consolidate longstanding links with colleagues in Europe, including researchers working with the European Observatory on Homelessness (n.d.) which is based with FEANTSA, the European Federation of National Homelessness Agencies (FEANTSA, n.d.). We have also been privileged to forge new links with researchers in our field from different disciplines and research networks beyond Europe. Such research networks appear to be expanding and to have extensive reach around global regions, testifying to the vibrancy of the sub-discipline of homeless- ness studies, and also sadly to the continuing and pervasive challenge of this social problem. The resulting collection of papers present a wide range of new evidence on homelessness including theoretical, methodological and empirical contributions which we hope will prove influential in terms of both scholarship and potential to enhance policy making and service delivery to some of our most excluded citizens.

Our initial call for papers for this themed issue noted that homelessness remains an enduring social issue which has been analysed and interpreted from a wide range of theoretical and disciplinary perspectives. The analysis of homelessness in relation to social exclusion emerged in the 1990s in parallel with European Union debates on the dynamics of poverty and the multidimensional nature of exclusion from social, economic and civic spheres of participation for some groups in society (Berghman, 1995; Cousins, 1998; Levitas, 1996). So- 
cial inclusion analysis helped to shed light on the complexity of homelessness as a multifaceted social issue impacting on, and relating to, housing, employment, income and social and family life; with those experiencing homelessness some of the most excluded citizens (Pleace, 1998). More recently, broader issues of inequality became a focus for the analysis of welfare policy and homelessness (O'Sullivan, 2011; Pleace, 2011). An aim of this themed issue was to revisit our understanding of homelessness, through a social inclusion lens, particularly in the period following the 2008 global financial crisis and subsequent austerity measures. However, the scope of this themed issue embraces a range of contemporary approaches to understanding homelessness as well as examining policy challenges and innovative interventions to prevent or alleviate homelessness.

The issue brings together articles that encompass diverse social issues linked to homelessness and also examine homelessness in various parts of the world beyond Europe (e.g. Brazil, Canada, and Japan). The articles tackle the issue of social inclusion and social exclusion of homeless or previously homeless people in different ways. As a response to homelessness, the Housing First approach has grown in influence in the USA and Europe in recent years and in our first paper, Quilgars and Pleace (2016) analyse existing research evidence to assess how effective the Housing First approach is, in ultimately ensuring social inclusion as people move out of homelessness. Christian, Abrams, Clapham, Thomas, Nayyar and Cotler (2016) also examine the effectiveness of services for homeless people but focus on the behavioural and psychological precursors that influence decisions of homeless people in their involvement with services and, in the end, their social inclusion. In our third contribution, Macías Balda (2016) also sees social inclusion as a goal of service provision and critically reflects on how local homelessness services are addressing the needs of people with complex needs. Following these three contributions from the UK context, Ursin's (2016) multi-method and ethnographic research on street youth in Brazil uncovers considerable complexity in patterns of inclusion and exclusion of homeless youth, while Okamoto's (2016) contribution reviews the broader debates around the problem of social exclusion and housing exclusion in the Japanese context.

A number of contributions focus on the more hidden or less researched homeless populations, such as sofa surfing among young people in the UK (Clarke, 2016) and rural homeless in Canada (Waegemakers Schiff, Schiff, \& Turner, 2016). Abramovich's (2016) paper on the development of policy towards homeless LGBT youth in Alberta, Canada, highlights an under-researched dimension of homelessness and also addresses related policy formation issues while Paradis (2016) (also in the Canadian context) critiques the crucial issue of the extent to which the voices of homeless persons themselves are heard in research and policy development through her case study of participation in homelessness conferences.
Finally, Anderson, Dyb and Finnerty (2016) present a three-country comparison of homelessness policy and outcomes across Scotland, Norway and Ireland, through the lens of institutionalism and path-dependency.

The papers gathered in this themed issue come from a range of disciplines (geography, sociology, psychology, social policy) with some embracing cross-disciplinary approaches (notably Christian et al., 2016). They tackle core conceptual issues such as defining and measuring homelessness (Anderson et al., 2016; Clarke, 2016); as well as the emerging challenges of understanding and responding to a wide and complex range of needs which homeless people may have, beyond a need for housing (Christian et al., 2016; Macías Balda, 2016; Quilgars \& Pleace, 2016). Going forward, the monitoring and evaluation of the impacts of differing policy and practice responses to homelessness remains challenging albeit with some methodological progress identified (Christian et al., 2016; Quilgars \& Pleace, 2016). There are clearly still challenges in understanding complex needs and responding in an integrated way, as well as a continuing need for better evaluation and measurement of the impact of services and outcomes for homeless people. While homelessness services may still lack an effective institutional framework that would enable them to improve their work (Macías Balda, 2016), Christian et al. (2016) have concluded that services which target and support the whole person can contribute to a virtuous cycle that increases wellbeing, wider social capital, and ultimately social inclusion.

Our collection suggests a continuing need for more research on participation and involvement of homeless people in research and in policy and service development. The benefits of acknowledging the views of homeless people are not yet fully utilised (Paradis, 2016). Exclusionary mechanisms persist (for example in the Brazilian case), including labelling and social stigma, but recognising the capacity/potential for empowerment and inclusion to develop from street homelessness (and a wide range of socio-economic conditions) also remains a theme for further exploration (Ursin, 2016).

A degree of resilience has been identified in the roles of institutions which tackle homelessness in different nations and their capacity to influence policy, even in face of severe economic crisis (Anderson et al., 2016). However, the comparative analysis of homelessness policy and its impacts within and across nation states remains a challenge for homelessness research with considerable scope for further cross-national and longitudinal research on understanding homelessness and evaluating policy responses.

Above all, access to good quality and affordable accommodation is a fundamental dimension of social inclusion, as evidenced across this collection of papers. Finally, as editors we also see important policy-relevant findings and recommendations inherent in all contributions which have potential to continue to improve our understanding of homelessness and the work of home- 
lessness services to challenge exclusion, deliver better results and achieve social inclusion for homeless people.

We are extremely grateful to the authors for their contributions, to a large pool of referees who contributed invaluable reviews, and to the Social Inclusion editorial team for inviting this thematic issue and supporting the editorial process.

\section{Conflict of Interest}

The authors declare no conflict of interest.

\section{References}

Abramovich, A. (2016). Preventing, reducing and ending LGBTQ2S youth homelessness: The need for targeted strategies. Social Inclusion, 4(4), 86-96.

Anderson, I., Dyb, E., \& Finnerty, J. (2016). The 'arc of prosperity' revisited: homelessness policy change in North Western Europe. Social Inclusion, 4(4), 108124.

Berghman, J. (1995). Social exclusion in Europe: Policy context and analytical framework. In G. Room (Ed.), Beyond the threshold: The measurement and analysis of social exclusion (pp. 10-28). Bristol: Policy Press.

Christian, J., Abrams, D., Clapham, D., Thomas, S., Nayyar, D., \& Cotler, J. (2016). Intentions to move from homelessness to social inclusion: The role of participation beliefs, attitudes and prior behaviour. Social Inclusion, 4(4), 16-27.

Clarke, A. (2016). The prevalence of rough sleeping and sofa surfing amongst young people in the UK. Social Inclusion, 4(4), 60-72.

Cousins, C. (1998). Social exclusion in Europe: Paradigms of social disadvantage in Germany, Spain, Sweden and the United Kingdom. Policy and Politics, 26(2), 127-146.

European Federation of National Homelessness Agencies. (n.d.). Retrieved from http://www.feantsa.org
European Observatory on Homelessness. (n.d.). Retrieved from http://www.feantsaresearch.org

European Network for Housing Research group on 'Welfare Policy, Homelessness and Social Exclusion'. (n.d.). Retrieved from http://www.enhr.net/ welfarepolicy.php

Levitas, R. (1996). The concept of social exclusion and the new Durkheimian hegemony. Critical Social Policy, 16(1), 5-20.

Macías Balda. (2016). Complex needs or simplistic approaches? Homelessness services and people with complex needs in Edinburgh. Social Inclusion, 4(4), 28-38.

O’Sullivan, E. (2011). Housing and social inequality in Europe. In I. Anderson \& D. Sim (Eds.), Housing and inequality (pp. 81-94). Coventry: Chartered Institute of Housing.

Okamoto, Y. (2016). Japanese social exclusion and inclusion from a housing perspective. Social Inclusion, 4(4), 51-59.

Paradis, E. (2016). Outsiders within: Claiming discursive space at national homelessness conferences in Canada. Social Inclusion, 4(4), 97-107.

Pleace, N. (1998). Single homelessness as social exclusion: The unique and the extreme. Social Policy and Administration, 32(1), 46-59.

Pleace, N. (2011). Homelessness and Inequality. In I. Anderson \& D. Sim (Eds.), Housing and inequality (pp. 187-221). Coventry: Chartered Institute of Housing.

Quilgars, D., \& Pleace, N. (2016). Housing First and social integration: A realistic aim? Social Inclusion, 4(4), 515.

Ursin, M. (2016). Contradictory and intersecting patterns of inclusion and exclusion of street youth in Salvador, Brazil. Social Inclusion, 4(4), 39-50.

Waegemakers Schiff, J., Schiff, R., \& Turner, A. (2016). Rural homelessness in Western Canada: Lessons learned from diverse communities. Social Inclusion, $4(4), 73-85$.

\section{About the Authors}

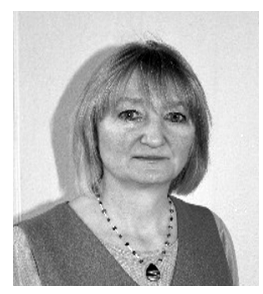

Isobel Anderson is Chair in Housing Studies and Associate Dean (Research) in the Faculty of Social Sciences at the University of Stirling, Scotland. She was founder/co-ordinator of the working group on Welfare Policy, Homelessness and Social Exclusion within the European Network for Housing Research (2003-2013) and is currently a Member of the International Advisory Committee of the European Journal of Homelessness and a board member of Homeless Action Scotland.

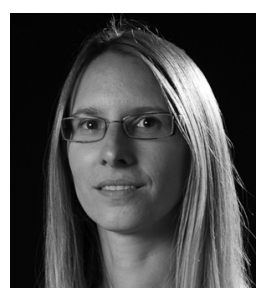

Maša Filipovič Hrast is Chair in Sociology and researcher in Centre for Welfare Studies at the Faculty of Social Sciences, University of Ljubljana, Slovenia. She lectures and graduate and postgraduate level on social policy, social inclusion and social problems. She has been part of the European Observatory on Homelessness (FEANTSA) and is member of the Women Homelessness European Network. 


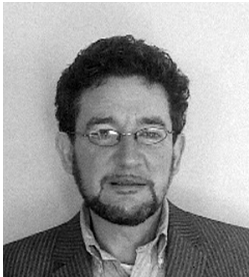

Joe Finnerty is Course Director of the Higher Diploma in Social Policy in the School of Applied Social Studies, University College Cork. His research interests are principally in the areas of housing and homelessness, poverty and social exclusion, and quantitative research methods. He is a coordinator of the Welfare Policy, Homelessness and Social Exclusion working group of the European Network of Housing Research, is Ireland correspondent for the European Observatory on Homelessness, and sits on the Cork Kerry Youth Out of Home Forum. 